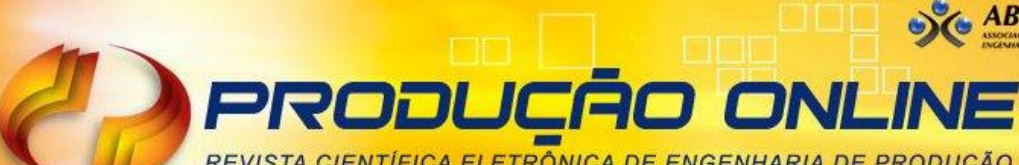 REVISTA CIENTIFICA ELETRÓNICA DE ENGENHARIA DE PRODUÇÃO ISSN 1676-1901
}

\section{GERAÇÃO Z E OS SEUS IMPACTOS NA CULTURA ORGANIZACIONAL}

\section{GENERATION Z AND ITS IMPACTS ON ORGANIZATIONAL CULTURE}

\author{
Gustavo Mello Saltoratto* E-mail:gustavomsaltoratto@gmail.com \\ Tamara Gaschler* E-mail: ta.gaschler@gmail.com \\ Virgínia do Socorro Motta Aguiar* E-mail: virginia-aguiar@uol.com.br \\ Maria Célia de Oliveira*E-mail: mariaceliaoliveira03@gmail.com \\ *Universidade Presbiteriana Mackenzie, São Paulo, SP
}

\begin{abstract}
Resumo: Com a chegada da "Era da Informação", as empresas passaram a considerar os funcionários como agentes ativos, responsáveis pelo processamento das informações e pela constituição da vantagem competitiva. Entretanto, conflitos surgem no ambiente de trabalho devido às diferenças culturais entre os colaboradores, que pertencem a diferentes gerações. A Geração Z, composta por aqueles nascidos após 1995 e caracterizados por terem crescido com a internet, está ingressando no mercado de trabalho atual, e por possuir características próprias, provavelmente haverá um incremento das diferenças culturais entre as gerações. Com o objetivo de analisar o perfil da Geração Z, foi realizado um estudo de caráter descritivo, de natureza quali-quantitativa, com 76 alunos de um curso de Engenharia de Produção de uma universidade privada da cidade de São Paulo, a fim de verificar quais são as características desta geração e o tipo de mudança que a mesma poderá promover na cultura das organizações. Com os resultados obtidos, foi possível descrever a geração com maior assertividade e também fomentar um cenário sobre seus integrantes como futuros líderes das organizações.
\end{abstract}

Palavras-chave: Geração Z. Cultura Organizacional. Engenharia de Produção

Abstract: Starting with the arrival of the "Information Era", companies have started to see their employees as active agents, responsible for processing information and for the creation of competitive advantage. However, conflicts began to arise on workplaces, due to the cultural differences between the staff, which belong to different generations. The Generation Z, consisting of those who were born post 1995 and characterized by having grown up surrounded by the internet, is starting to get into the job market, and because they have their own features, it will probably increase cultural gaps between generations on work. Looking forward to analyze the current profile of Generation Z, a qualitativequantitative study has been made amongst 76 students from an Industrial Engineering course in a private university located in São Paulo city, in order to verify this generation's characteristics and what types of transformations they can foster on the organizational culture. Those results enabled an assertive description of this generation, and it enabled the creation of scenarios about this generation as future leaders.

Keywords: Generation Z. Organizational Culture. Industrial Engineering.

\section{INTRODUÇÃO}

A história da humanidade é marcada por eventos que acontecem nos âmbitos político, social e econômico, os quais acabam por moldar e influenciar os padrões de vida e os costumes da população cerceada por tais acontecimentos. O aumento 
exponencial de tecnologias, impulsionado principalmente pela globalização, fez com que fosse iniciada uma era que, segundo Chiavenato (1999), é definida como a Era da Informação. Tendo início em 1990, suas principais características são as rápidas e imprevisíveis mudanças causadas pela tecnologia da informação, fazendo com que dados e informações cruzassem fronteiras quase que imediatamente, levando a uma rede de conexão mundial. Essa rede faz com que todos tenham acesso à informação ao mesmo tempo, e, com um olhar para os negócios, a vantagem competitiva deixou de ser a posse da informação, fazendo com que as empresas focassem no processamento das mesmas e na sua capacidade de gerar, armazenar e distribuir conhecimento. Segundo Bartlett e Ghoshal (1987), essa capacidade está se tornando um recurso crítico e valioso ativo competitivo, podendo ser atingido por meio do capital humano e de técnicas de gestão. O conhecimento se torna a principal ferramenta para a tomada de decisão nas organizações, e os colaboradores, que são os detentores deste conhecimento, se transformam em recursos críticos para a vantagem competitiva das organizações bem-sucedidas.

Neste cenário, as organizações começam a ver os funcionários como agentes ativos e responsáveis pelo seu êxito, e a denominada área de Recursos Humanos cede lugar para a gestão de pessoas, e estas, que estão inseridas nas empresas, são diferentes entre si, o que acaba gerando conflitos e divergências que prejudicam a produtividade e o ambiente de trabalho. Parte desses conflitos surgem pela diferença cultural entre os colaboradores, devido às diferentes gerações que convivem no mesmo ambiente, sendo necessário entendê-las e criar políticas e práticas que se adaptem às mesmas (CAZALEIRO, 2011). Atualmente, existem quatro gerações ativas no mercado de trabalho, que são os Baby Boomers, a Geração X, a Geração $Y$ e a Geração Z (ADDOR, 2011; HALF, 2015).

Nos últimos anos, estudos têm sido feitos sobre a Geração $\mathrm{Y}$, com o objetivo de identificar as suas características e como estas impactam o mercado de trabalho e os costumes da sociedade em geral. A Geração Z, caracterizada por aqueles que já nasceram em um mundo conectado, com uma necessidade quase intrínseca de acesso à internet (SERRANO, 2010), está ingressando no mercado de trabalho. Porém, nota-se que não existem, no momento, diversos estudos no Brasil sobre o comportamento desta geração e suas expectativas de carreira profissional, que são 
informações relevantes no momento do planejamento da gestão de pessoas das empresas. Com base nessas premissas, este trabalho definiu as seguintes problemáticas a serem estudadas: O perfil dos alunos de Engenharia de Produção de uma universidade privada da cidade de São Paulo é compatível com o perfil definido pela literatura acerca da Geração Z? Quais os impactos do perfil desta geração na cultura de uma organização?

Para responder a estas questões, o objetivo geral deste trabalho é traçar o perfil da Geração Z, com base nos alunos de Engenharia de Produção de uma universidade privada da cidade de São Paulo e analisar seus possíveis impactos na cultura organizacional das empresas.

\section{DESENVOLVIMENTO}

Neste tópico de desenvolvimento do trabalho estão apresentados os seguintes elementos: fundamentação teórica; metodologia de pesquisa e a apresentação e discussão dos resultados. A fundamentação teórica foi construída a partir da pesquisa bibliográfica que foi desenvolvida no início do trabalho, constituindo a base teórica para o trabalho. A metodologia de pesquisa apresenta a caracterização da pesquisa e o respectivo método para o desenvolvimento da mesma. Finalmente a apresentação e discussão dos resultados apresenta a análise descritiva dos resultados coletados a partir do questionário que foi aplicado aos alunos do curso de Engenharia de Produção de uma universidade privada de São Paulo.

\subsection{Fundamentação Teórica}

Existem três acepções principais para o conceito de geração, desconsiderando o significado da palavra de gerar ou produzir algo, de acordo com o trabalho de Forquin (2003). A primeira noção é a acepção "genealógica" de geração, que é o grau de filiação entre os indivíduos, as gerações das famílias, ligadas por um ancestral comum. Esta filiação demonstra um grande poder de estruturação social, porém não tem fortes relações com o fator temporal, pois devido a fatores biológicos, como o período de procriação, é possível que uma geração contenha indivíduos de idades diferentes. A segunda acepção, utilizada na língua francesa, é o sentido de categoria 
de uma idade específica, um período da vida, nomeada corriqueiramente como geração jovem, adulta ou velha. Nessa visão de idade, é levantada a ideia de que a interação entre as gerações ocorre dos mais velhos que condensam, mediam e apropriam a herança cultural e as transmitem para os mais novos.

A terceira e última acepção levantada pelo autor, é o conceito histórico e sociológico, que "[...] designa um conjunto de pessoas que nasceram mais ou menos na mesma época e que têm em comum uma experiência histórica idêntica e/ou uma proximidade cultural” (FORQUIN, 2003, p. 03). Essa acepção se aproxima muito do conceito de "coorte" usado por Meredith, Schewe e Karlovich (2002, apud MENETTI, 2013), em que as experiências compartilhadas entre o fim da adolescência e o início da fase adulta moldam os valores que serão carregados durante o resto da vida.

\subsubsection{Geração Z}

A Geração Z, também conhecida como centennials, é delineada cronologicamente como os indivíduos nascidos nos anos 1990 (HALF, 2015), ou, mais especificamente, após 1995 (ADECCO, 2015). O termo "Geração Z" vem da palavra zapping, termo que representa a mudança constante de canais na televisão, ou seja, mostra a característica de obter informações e se desinteressar pelas mesmas rapidamente.

Estes geralmente são filhos de pais protetores, o que traz fortes influências nas suas personalidades, pois esses pais passaram por momentos de dificuldade em sua infância, forçando-os a terem atitudes que tragam segurança aos seus filhos para que não passem pelas mesmas adversidades. Isso é mostrado pela pesquisa de Half (2015), na qual $82 \%$ dos membros da Geração $Z$ que responderam à pesquisa dizem que esperam conselhos de seus pais na hora da escolha profissional. Todos esses fatores fizeram com que a Geração $Z$ fosse mais consciente e que o seu otimismo fosse trocado pelo pragmatismo (WILLIAMS, 2015).

Em meio a crises e dificuldades, essa geração também cresceu em um ambiente submetido a profundas mudanças que formaram uma sociedade multicultural. A sociedade em que estão inseridos vem quebrando antigos paradigmas 
e fazendo com que essa geração tenha um senso forte de responsabilidade social (SERRANO, 2010; WILLIAMS, 2015).

Outra característica marcante na Geração Z é a tecnologia, que vem moldando seus hábitos diários. Diferentemente das gerações predecessoras, essa geração já nasceu conectada e cercada pela internet. São os chamados de "nativos digitais", segundo Prensky (2001, apud COLBERT; YEE; GEORGE; 2016), pois não se lembram da primeira vez em que acessaram a internet. Além disso, a Geração Z é marcada pelas redes sociais e smartphones, fazendo com que tivessem fácil acesso a qualquer tipo de informação. Sua infância e adolescência foram marcadas pelas redes sociais, o que significa que grande parte de suas relações nasceram de sites como Facebook ou Instagram (WILLIAMS, 2015).

Possibilitado pelo uso destes aparelhos, o fluxo de informação que chega a essa geração é excessivamente alto, fato que concebe um perfil marcado pelo imediatismo, pois sempre há a possibilidade de se estar atualizado com as últimas notícias e acontecimentos. Esse perfil pode ser benéfico, pois cria certo tipo de proficiência e habilidade em processar e manipular o bombardeamento de informação, algo que se mostra forte na Geração $Z$ devido à sua naturalidade com a internet e a tecnologia. Porém, também fomenta um perfil que fica rapidamente desinteressado pela informação e que não necessariamente está assimilando e guardando aquilo que Ihes é mostrado, o que é afirmado por Carr (2011, p. 227), "[...] somos apressados para ir adiante até um outro pedaço de informação relacionada, e outra, e outra. $\mathrm{O}$ garimpo superficial do 'conteúdo relevante' substitui a lenta escavação do significado”.

Diferente das gerações anteriores, a Geração Z ainda é nova e está começando a entrar no mercado de trabalho, não sendo possível afirmar com certeza como será o seu perfil nestes ambientes. Diversos estudiosos fizeram pesquisas com esses indivíduos, de modo a achar um resultado de características as quais essa geração espera ter e encontrar no trabalho. As premissas mostradas nos parágrafos a seguir são baseadas nas pesquisas de Half (2015) e Addeco (2015), realizadas com indivíduos da Geração Z, e que abordam diversos pontos que se relacionam ao mercado de trabalho e suas características.

A Geração Z é caracterizada por ser tão multitask quanto a sua geração anterior, pois, conforme mostrado anteriormente, cresceu em um ambiente cercado 
por tecnologia e muita informação. Também é uma geração muito criativa e empreendedora, trazendo novas soluções e ideias para problemas que já possuem métodos tradicionais que trazem bons resultados, fazendo com que surjam inovações nos processos existentes.

Esta geração preza pela independência no trabalho, pois acreditam que precisam mostrar resultados e provarem seu valor, mas ainda assim precisam ser ensinados e guiados, pois é uma geração acostumada a ser conduzida em todos os aspectos de sua vida, seja escolar ou familiar, e também são ótimos ouvintes. Ao contrário do esperado, a Geração Z prefere, no trabalho, ter conversas "cara a cara" do que por mensagens ou e-mails. O seu convívio diário com as redes sociais e as mensagens instantâneas faz com que a conversa "cara a cara" seja mais rica e construa relações mais genuínas.

Acredita-se ainda que as soft skills, que são as competências sociais e comportamentais, são mais importantes no trabalho que as hard skills, que são as competências técnicas, mesmo que sejam marcados por um forte conhecimento técnico devido ao alto nível de educação dessa geração. Essa característica pode ser explicada pela observação de seus antecessores, que sofreram com sua entrada no mercado de trabalho pela falta das soft skills. Esse contexto é bem explicado pela frase de Baumann (2015), citado no trabalho de Half (2015, p. 08), para o qual, na atual sociedade "graduar com um diploma não te diferencia como antes".

A Geração $Z$ espera ter que trabalhar mais arduamente que as gerações anteriores, devido ao contexto histórico conturbado e competitivo em que estão inseridos. Também esperam ter que trabalhar até os setenta anos, devido à observação de seus pais e avós, que se aposentaram, mas tiveram que voltar ao trabalho para suprir a renda.

Um dos fatores que destacam a Geração $Z$ na escolha de um emprego é a estabilidade financeira, e essa característica pode ser explicada pelo árduo período econômico dos últimos anos. Isso faz com que se busquem empregos em empresas de médio ou grande porte, que garantam a desejada estabilidade. Ao mesmo tempo, estes também buscam uma empresa que cause um impacto positivo no mundo e na sua sociedade. 
Um aspecto marcante dessa geração é a alta rotatividade, pois grande parte de seus integrantes espera passar menos de três anos em seu primeiro emprego. Contudo, essa geração busca crescimento e oportunidades de uma carreira rápida e estruturada, portanto, se as empresas forem capazes de oferecer isso aos seus colaboradores da Geração Z, potencializarão a retenção e a fidelidade.

\subsubsection{Cultura organizacional}

A cultura organizacional se destacou nas discussões acadêmicas e de negócios a partir da década de 1980, com a crescente competitividade entre as indústrias, quando administradores perceberam que mesmo após operarem todo tipo de mudança no negócio, as empresas não apresentavam um desempenho comparável ao dos anos anteriores, e que seria necessário realizar mudanças nos valores comuns, nos símbolos e nas crenças das pessoas que fazem parte de uma organização (WOOD, 1992). Com o objetivo de representar a cultura organizacional com toda a sua complexidade, Schein $(2009$, p. 16) definiu de forma geral a cultura organizacional como:

Um padrão de suposições básicas compartilhadas, que foi aprendido por um grupo à medida que solucionava seus problemas de adaptação externa e de integração interna. Esse padrão tem funcionado bem o suficiente para ser considerado válido e, por conseguinte, para ser ensinado aos novos membros como o modo correto de perceber, pensar e sentir-se em relação a esses problemas.

Kotter e Heskett (1994) defendem que a estrutura da cultura organizacional possui apenas dois níveis, conforme o Quadro 1, que se diferenciam pela visibilidade e resistência a mudanças. 
Quadro 1 - A Cultura e uma Organização

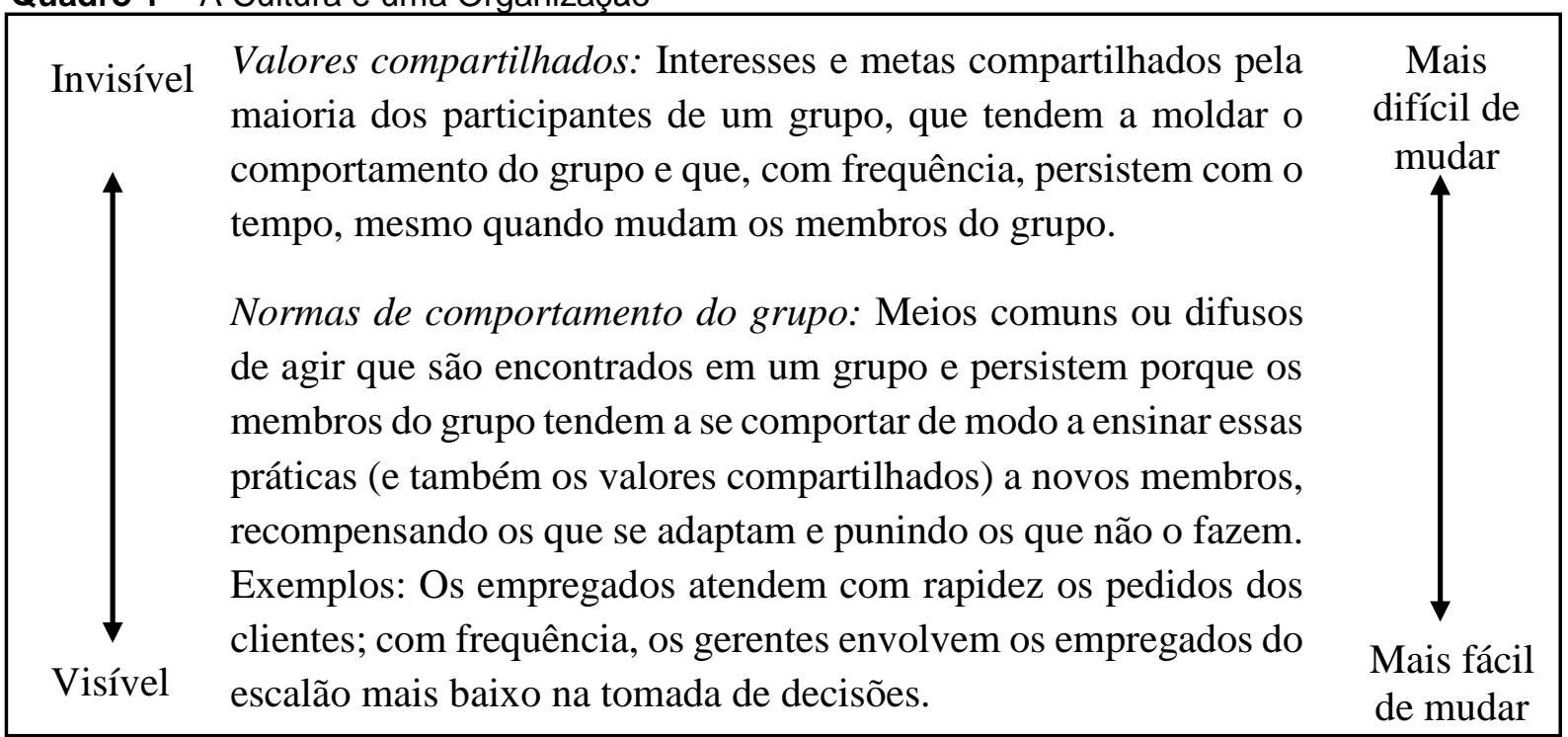

Fonte: Kotter e Heskett (1994, p. 05)

Para Schein (2009), a cultura organizacional começa a partir da imposição das suposições, crenças e valores dos líderes nos demais integrantes do grupo, porém, a cultura só se estabelece caso o grupo passe por experiências de sucesso que validem os valores dos líderes, transformando-os em valores comuns. Caso falhem, outra pessoa se tornará o líder, impondo suas crenças e valores, e assim sucessivamente, até a equipe obter sucesso, consolidando a cultura.

Diversos autores (SCHEIN, 2009; FLEURY \& FLEURY, 2011; BILHIM, 1995; DRUCKER, 2003) defendem que o processo de mudança da cultura de uma organização é lento, complexo e gera insegurança nos colaboradores. Segundo Dias (2013), a mudança cultural pode recuperar empresas que se encontram em conflito entre os próprios valores organizacionais e as demandas do seu entorno.

Em uma organização, os seus integrantes buscam solucionar crises utilizando os métodos já conhecidos e enraizados na cultura organizacional. Porém, quando novos dilemas não podem ser resolvidos pelos métodos habituais, cria-se um estado de insegurança, pois os integrantes precisarão desaprender a forma culturalmente aceita de resolver problemas para buscar novas soluções e aprender novos métodos. Segundo Schein (2009), uma vez que uma nova solução for empregada e tiver resultados satisfatórios, ela fará parte da cultura desta organização.

A liderança é fundamental na formação, manutenção e mudança da cultura organizacional (DIAS, 2013). Assim, a escolha dos líderes de uma organização pode 
determinar a capacidade da mesma a sobreviver, pois as mudanças ocorrerão com maior frequência e serão cada vez mais difíceis de se prever (DRUCKER, 2003).

Segundo Hamel e Prahalad (1999), as próximas décadas serão repletas de oportunidades para aprender e se desenvolver, porém aqueles que resistirem às mudanças não farão parte do futuro das organizações. Os líderes do futuro deverão ter, no mínimo, as seguintes características:

- Raciocínio Sistêmico: Ter a capacidade de enxergar o todo, percebendo ligações entre as partes e ser capaz de imaginar o futuro, combinando a capacidade analítica e a intuitiva e harmonizando informações mensuráveis e imensuráveis.

- Competência Intercultural: Ter consciência que outras culturas não possuem os mesmos valores e crenças. Falar diversos idiomas e ter conhecimento em história, religião e arte facilitam o desenvolvimento desta competência.

- Treinamento Intensivo e Contínuo: A meia vida do que se conhece será extremamente curta, assim será importante cada vez mais que os líderes aprendam novas técnicas, ideias e tecnologias. A educação contínua se torna fundamental e indispensável.

- Padrões Pessoais e de Comportamento: Uma organização não pode sobreviver sem padrões de comportamento claros e definidos. Além de estabelecer os padrões mínimos de valores e comportamentos, o líder deverá demonstrar o mais elevado padrão pessoal da excelência.

Estas características determinam que o líder esteja apto para conduzir uma organização com o meio cada vez mais competitivo e imprevisível, tornando-se um pensador, e não apenas um executor.

\subsection{Metodologia da Pesquisa}

Para desenvolver este estudo, primeiramente foi feita uma pesquisa bibliográfica, para estabelecer uma base teórica para a elaboração das premissas do trabalho e, segundo Lakatos e Marconi (2010), contextualizar o leitor dos conceitos e trabalhos já realizados sobre o tema. A pesquisa bibliográfica possibilitou o maior 
entendimento sobre a problemática do estudo, aprofundamento nas bases teóricas da cultura e mudança organizacional e, ao mesmo tempo, buscar fontes para caracterizar a Geração Z.

Posteriormente, foi realizada uma pesquisa descritiva, "buscando descrever as características de determinada população ou fenômeno ou o estabelecer relações entre variáveis" (GIL, 2008, p. 28). Para isso, uma das características é a padronização da coleta de dados, que pode ser feita por meio de questionários, entrevistas e observações (ANDRADE, 2010). Esta pesquisa foi caracterizada como uma pesquisa de campo, pois baseia-se na observação dos fatos tal como ocorrem na realidade. Para isso, o pesquisador coleta os dados em campo, diretamente no local da ocorrência dos fenômenos (ANDRADE, 2010).

O estudo tem ainda caráter qualitativo e quantitativo, pois utiliza recursos de ambas as metodologias. Segundo Goldenberg (2004) a metodologia qualitativa possibilita o aprofundamento da compreensão de um grupo estudado, levando em consideração a complexidade e especificidade das ciências sociais e suas interações. Já a pesquisa quantitativa recorre à linguagem matemática para descrever as causas de um fenômeno, as relações entre variáveis, etc. Entende-se que a utilização conjunta da pesquisa qualitativa e quantitativa permite obter mais informações do que se poderia conseguir optando por uma das metodologias (FONSECA, 2002).

O instrumento de pesquisa selecionado para a coleta de dados foi um questionário, elaborado pelos pesquisadores a partir da revisão bibliográfica, por meio de uma amostra não probabilística por acessibilidade. Esse questionário foi aplicado em um total de 76 alunos de um curso de Engenharia de Produção de uma universidade privada da cidade de São Paulo.

O questionário foi organizado em três seções, sendo a primeira com informações básicas dos participantes, a segunda sobre características pessoais, e a terceira formada por características que os mesmos julgam necessárias ou importantes em um ambiente corporativo.

Para cada afirmação os respondentes assinalavam valores $5,4,3,2$ ou 1, expressos em escala do tipo Likert, que correspondem respectivamente às respostas Concordo Totalmente, Concordo Parcialmente, Indiferente, Discordo Parcialmente e 
Discordo Totalmente, indicando o grau de concordância ou discordância de acordo com as variáveis e atitudes relacionadas ao objeto.

Quanto à análise dos dados obtidos, as afirmações foram dispostas em tabelas, com suas respectivas quantidades de respostas, de modo a facilitar a sua interpretação. A partir de cada tabela, foi realizada uma análise descritiva dos dados, por meio das porcentagens de respostas observadas e moda das respostas.

\subsection{Resultados e Discussões}

Como o objetivo do presente estudo é analisar os integrantes da Geração Z na universidade em questão e suas características, apenas foram usados dados de respondentes que nasceram no ano de 1995 para frente, ou seja, a amostra que se encaixa no período descrito pela literatura para essa geração.

Após a coleta e filtragem dos dados, foi obtida uma amostra distribuída entre $53 \%$ de alunos nascidos em 1995, 38\% nascidos no ano de 1996 e $9 \%$ com ano de nascimento 1997. Quanto ao gênero, tivemos $51 \%$ de respondentes femininas, contra $49 \%$ masculinos, distribuídos do quinto ao nono semestre conforme Figura 1.

Figura 1 - Descrição da amostra

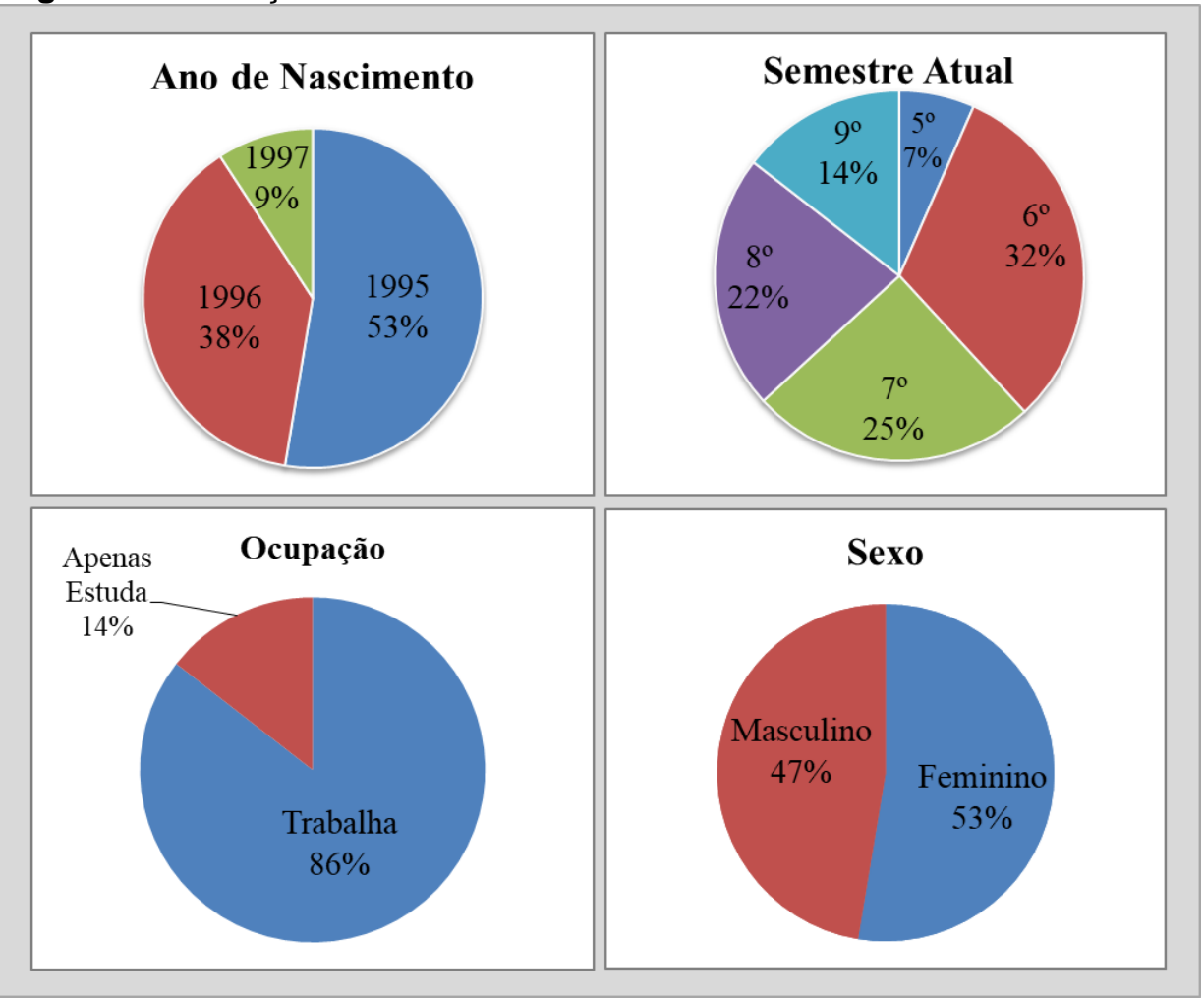

Fonte: Autores (2017) 
De acordo com a Figura 1 é possível observar que grande parte dos participantes já está no mercado de trabalho, o que fez com que as respostas do instrumento de análise fossem respondidas mais facilmente e com maior assertividade. Também é possível ressaltar que, como a maioria dos participantes já está na metade final do curso, os mesmos já possuem conhecimento para interpretação correta das perguntas, contribuindo positivamente com esse estudo. A presença equilibrada de participantes de ambos os sexos legitima a amostra, sendo possível fazer conclusões que sejam aplicáveis à ambos os gêneros.

Segundo a revisão da literatura, a Geração $Z$ não coleta informação de modo profundo, apenas aprende de modo superficial tudo que lhes é mostrado. Observando-se os resultados obtidos, é possível verificar que essa afirmação não é verdadeira. Os engenheiros de produção da Geração $Z$ não necessariamente coletam informações de modo raso, o que é visto pela neutralidade com uma leve tendência para o "Discordo" das respostas, com moda 2, exposto na Tabela 1. Essa diferença entre a literatura, afirmada por Carr (2011), e a presente pesquisa pode ser explicada pelo documento elaborado pela ABEPRO (1998), que diz que Engenheiros de Produção devem recorrer a conhecimentos especializados de várias áreas de modo a executar suas tarefas com assertividade.

Tabela 1 - Resultados das Afirmações sobre Relação com Internet e Informação

\begin{tabular}{|c|c|c|c|c|c|c|}
\hline & 1 & 2 & 3 & 4 & 5 & Moda \\
\hline $\begin{array}{l}\text { Me recordo da primeira vez que } \\
\text { acessei a internet. }\end{array}$ & $53,9 \%$ & $15,8 \%$ & $7,9 \%$ & $7,9 \%$ & $14,5 \%$ & 1 \\
\hline $\begin{array}{l}\text { O uso da internet é essencial em meu } \\
\text { cotidiano. }\end{array}$ & $0,0 \%$ & $1,3 \%$ & $0,0 \%$ & $14,5 \%$ & $84,2 \%$ & 5 \\
\hline $\begin{array}{l}\text { Consumo informação, majoritamente, } \\
\text { por meu smartphone. }\end{array}$ & $0,0 \%$ & $2,6 \%$ & $3,9 \%$ & $44,7 \%$ & $48,7 \%$ & 5 \\
\hline $\begin{array}{l}\text { Acredito que a coleta superficial de } \\
\text { informações é mais importante do que } \\
\text { o aprofundamento nas mesmas. }\end{array}$ & $23,7 \%$ & $44,7 \%$ & $15,8 \%$ & $13,2 \%$ & $2,6 \%$ & 2 \\
\hline $\begin{array}{l}\text { Com o excesso de informações, os } \\
\text { assuntos se tornam rapidamente } \\
\text { desinteressantes para mim. }\end{array}$ & $14,5 \%$ & $28,9 \%$ & $21,1 \%$ & $23,7 \%$ & $11,8 \%$ & 2 \\
\hline $\begin{array}{l}\text { A orientação dos pais é um fator } \\
\text { decisivo na escolha profissional. }\end{array}$ & $19,7 \%$ & $27,6 \%$ & $22,4 \%$ & $22,4 \%$ & $7,9 \%$ & 2 \\
\hline
\end{tabular}
Fonte: Autores (2017) 
Observa-se pela Tabela 1 a relação que a Geração $Z$ tem com a internet, que é reforçada pelo fato de que a maior parte, ou seja, 69,7\% dos respondentes, discorda parcial ou totalmente com a afirmação sobre se os mesmos lembram a primeira vez que usaram a internet. A afirmação sobre o uso da internet ser essencial no cotidiano teve uma concordância de $84,2 \%$ dos respondentes, principalmente por meio do uso de smartphone, onde $93,4 \%$ dos participantes concordaram ou concordam totalmente que o smartphone é o seu meio principal de acesso à internet e informações.

$\mathrm{Na}$ Tabela 2, observa-se que houve uma concordância da maioria quanto à característica de ser multitarefas, com moda 5 de concordância. Essa característica foi considerada como positiva no ambiente de trabalho, pois favorece a execução das tarefas em um ambiente dinâmico, tecnológico e com muita informação.

Tabela 2 - Resultados das Afirmações sobre Multitarefa e Criatividade

\begin{tabular}{lcccccc}
\hline & 1 & 2 & 3 & 4 & 5 & Moda \\
\hline $\begin{array}{l}\text { Me considero uma pessoa multitarefa. } \\
\begin{array}{l}\text { Ser multitarefas no trabalho é uma } \\
\text { característica indispensável. }\end{array}\end{array} 0,0,0 \%$ & $5,3 \%$ & $6,6 \%$ & $40,8 \%$ & $47,4 \%$ & 5 \\
$\begin{array}{l}\text { Procuro pensar "fora da caixa" sempre } \\
\text { que possível. }\end{array}$ & $1,3 \%$ & $3,9 \%$ & $10,5 \%$ & $42,1 \%$ & $38,2 \%$ & 4 \\
$\begin{array}{l}\text { Pensar "fora da caixa" é necessário no } \\
\text { mercado atual. }\end{array}$ & $1,3 \%$ & $3,9 \%$ & $6,6 \%$ & $34,2 \%$ & $53,9 \%$ & 5 \\
\hline
\end{tabular}

Fonte: Autores (2017)

Foi observado ainda que a maioria dos participantes possui a capacidade de "pensar fora da caixa", ou seja, pensarem em soluções criativas, com $84,2 \%$ de concordância, e que julgam essa capacidade como necessária no mercado de trabalho atual, tendo $88,2 \%$ de concordância. Ambas as respostas coincidem com o que é descrito na literatura, onde se afirma "que o engenheiro contemporâneo deve estar preparado para lidar com novos e imprevistos problemas da vida real, identificando, formulando e propondo soluções criativas e inovadoras a problemas mal formulados" (SIMON, 2004, p. 25).

Segundo Half (2015) e Addeco (2015), a Geração Z acredita que as soft skills, as competências sociais e comportamentais, são mais importantes no trabalho que as hard skills, os conhecimentos teóricos, porém não foi possível verificar essa informação com base nas respostas descritas na Tabela 3. Esse comportamento da 
amostra pode ser explicado pelas competências requeridas especificamente para um engenheiro. Simon (2004) defende que os futuros engenheiros devem ter uma formação sólida, com domínio do conhecimento técnico e específico da área, não podendo ser substituídos pela aquisição das demais habilidades, soft skills. Essa premissa se confirma por meio da análise da primeira afirmação da Tabela 3 , onde se observa que $84,2 \%$ dos respondentes consideram-se capazes de combinar a capacidade analítica com a intuitiva.

Tabela 3 - Resultados das Afirmações sobre Hard Skills e Soft Skills

\begin{tabular}{|c|c|c|c|c|c|c|}
\hline & 1 & 2 & 3 & 4 & 5 & Moda \\
\hline $\begin{array}{l}\text { Consigo combinar a capacidade } \\
\text { analítica com a intuitiva. }\end{array}$ & $1,3 \%$ & $3,9 \%$ & $10,5 \%$ & $57,9 \%$ & $26,3 \%$ & 4 \\
\hline $\begin{array}{l}\text { Uma das minhas qualidades é o } \\
\text { domínio do conhecimento técnico. }\end{array}$ & $0,0 \%$ & $9,2 \%$ & $28,9 \%$ & $42,1 \%$ & $19,7 \%$ & 4 \\
\hline $\begin{array}{l}\text { O conhecimento técnico é essencial } \\
\text { para o mercado de trabalho }\end{array}$ & $1,3 \%$ & $7,9 \%$ & $9,2 \%$ & $57,9 \%$ & $23,7 \%$ & 4 \\
\hline $\begin{array}{l}\text { Uma das minhas qualidades é o } \\
\text { domínio do conhecimento social e } \\
\text { comportamental. }\end{array}$ & $0,0 \%$ & $13,2 \%$ & $17,1 \%$ & $38,2 \%$ & $31,6 \%$ & 4 \\
\hline $\begin{array}{l}\text { O conhecimento social e } \\
\text { comportamental é essencial para o } \\
\text { mercado de trabalho }\end{array}$ & $0,0 \%$ & $6,6 \%$ & $13,2 \%$ & $32,9 \%$ & $47,4 \%$ & 5 \\
\hline
\end{tabular}

Segundo Nguyen e Pudlowski (1998), conhecer outras culturas, incluindo seus idiomas, histórias e religiões, é fundamental para ter sucesso no competitivo ambiente internacional. Observa-se na Tabela 4 que grande parte dos participantes concordou com as afirmações de competência intercultural, afirmando que os mesmos a possuem e acreditam que são necessárias no mercado atual. 
Tabela 4 - Resultados das Afirmações sobre Competência Intercultural

\begin{tabular}{lcccccc}
\hline & 1 & 2 & 3 & 4 & 5 & Moda \\
\hline $\begin{array}{l}\text { Tenho interesse em conhecer e } \\
\text { compreender outras culturas. }\end{array}$ & $0,0 \%$ & $6,6 \%$ & $3,9 \%$ & $32,9 \%$ & $56,6 \%$ & 5 \\
$\begin{array}{l}\text { É imprescindível conhecer e } \\
\text { compreender outras culturas para ter } \\
\text { sucesso profissional. }\end{array}$ & $6,6 \%$ & $7,9 \%$ & $5,3 \%$ & $51,3 \%$ & $27,6 \%$ & 4 \\
$\begin{array}{l}\text { Possuo conhecimento de idiomas, } \\
\text { história e religião. }\end{array}$ & $2,6 \%$ & $2,6 \%$ & $14,5 \%$ & $48,7 \%$ & $31,6 \%$ & 4 \\
$\begin{array}{l}\text { No ambiente organizacional, é } \\
\text { fundamental ter conhecimento de } \\
\text { idiomas, história e religião. }\end{array}$ & $0,0 \%$ & $13,2 \%$ & $6,6 \%$ & $50,0 \%$ & $30,3 \%$ & 4 \\
\hline
\end{tabular}

Fonte: Autores (2017)

Em relação à educação contínua, os líderes devem estar atualizados em relação a novas tecnologias, ideias e técnicas, pois as mudanças ocorrem de forma cada vez mais acelerada. A obtenção contínua de conhecimento se tornou uma vantagem competitiva tanto para as empresas, quanto para os profissionais. Além disso, é possível notar que a formação acadêmica deixou de ser um fator de vantagem competitiva no mercado. Pode-se afirmar que os respondentes possuem a característica de liderança de acordo com o citado acima, conclusão que é fortalecida pelo "peso" atribuído pela maioria dos entrevistados conforme apresentado na Tabela 5.

Tabela 5 - Resultados das Afirmações sobre Educação

\begin{tabular}{lcccccc}
\hline & 1 & 2 & 3 & 4 & 5 & Moda \\
\hline $\begin{array}{l}\text { Estudar é algo que pretendo fazer } \\
\text { durante a vida toda. }\end{array}$ & $3,9 \%$ & $6,6 \%$ & $14,5 \%$ & $38,2 \%$ & $36,8 \%$ & 4 \\
$\begin{array}{l}\text { Acredito que, atualmente, ter um } \\
\text { diploma é uma necessidade e não mais } \\
\text { um diferencial. }\end{array}$ & $1,3 \%$ & $1,3 \%$ & $6,6 \%$ & $15,8 \%$ & $75,0 \%$ & 5 \\
$\begin{array}{l}\text { No ambiente corporativo, ter um } \\
\text { diploma é um pré-requisito e não um } \\
\text { diferencial. }\end{array}$ & $1,3 \%$ & $2,6 \%$ & $5,3 \%$ & $19,7 \%$ & $71,1 \%$ & 5 \\
\hline
\end{tabular}

Fonte: Autores (2017)

Por conta do difícil momento econômico no qual a Geração Z se insere durante sua entrada no mercado de trabalho, essa geração acredita que precisa mostrar resultados e provar seu valor, e tal afirmação é confirmada na Tabela 6, com moda de 
resultados 5. Já como futuros líderes, essa geração deve, além de estabelecer padrões mínimos de valores e comportamentos, demonstrar o mais elevado padrão pessoal da excelência. Essa característica pode ser observada na geração pelo fato de mais de $90 \%$ dos entrevistados terem concordado ou concordado totalmente sobre a afirmação que os mesmos procuram entregar resultados acima do esperado.

Tabela 6 - Resultados das Afirmações sobre Excelência no Trabalho

\begin{tabular}{lcccccc}
\hline & 1 & 2 & 3 & 4 & 5 & Moda \\
\hline $\begin{array}{l}\text { A excelência é algo que almejo em } \\
\text { tudo que faço. }\end{array}$ & $0,0 \%$ & $1,3 \%$ & $5,3 \%$ & $36,8 \%$ & $56,6 \%$ & 5 \\
$\begin{array}{l}\text { Busco sempre entregar resultados } \\
\text { acima do esperado. }\end{array}$ & $0,0 \%$ & $1,3 \%$ & $7,9 \%$ & $30,3 \%$ & $60,5 \%$ & 5 \\
$\begin{array}{l}\text { Entregar resultados acima do esperado } \\
\text { é algo essencial. }\end{array}$ & $1,3 \%$ & $2,6 \%$ & $2,6 \%$ & $44,7 \%$ & $48,7 \%$ & 5 \\
\hline
\end{tabular}

Fonte: Autores (2017)

Quanto à responsabilidade social da Geração Z, é possível verificar na Tabela 7 que $86,8 \%$ dos participantes concordam totalmente que apresentam as características de justiça e de consciência em relação ao direito de todos da sociedade. É possível observar ainda que essa responsabilidade social se estende para o trabalho, pois, assim como afirmado sobre a Geração Z na literatura, os participantes revelaram que as ações sociais e os impactos que as empresas geram são um fator decisivo na escolha de um emprego.

Tabela 7 - Resultados das Afirmações sobre Responsabilidade Social

$\begin{array}{llllll}1 & 2 & 3 & 4 & 5 & \text { Moda }\end{array}$

Todos os cidadãos devem ter os mesmos direitos, independente do

$0,0 \% \quad 3,9 \% \quad 1,3 \% \quad 6,6 \% \quad 86,8 \% \quad 5$
sexo, cor ou orientação sexual.

É importante a empresa ter ações de $\quad \begin{array}{lllllll}1,3 \% & 5,3 \% & 11,8 \% & 35,5 \% & 46,1 \% & 5\end{array}$ responsabilidade social.

Fonte: Autores (2017)

Sobre a decisão profissional, observa-se na Tabela 8 que $72,4 \%$ dos participantes da Geração Z levam em conta a estabilidade financeira como fator decisivo na escolha de emprego. Diferente de seus predecessores, que buscavam 
empregos "dos sonhos", essa geração foca sua procura por empregos que lhes darão estabilidade, influenciados pelo período econômico conturbado em que estão inseridos.

Tabela 8 - Resultados das Afirmações sobre Escolha de Profissão e Comunicação

\begin{tabular}{lcccccc}
\hline & 1 & 2 & 3 & 4 & 5 & Moda \\
\hline $\begin{array}{l}\text { Estabilidade financeira é um fator } \\
\begin{array}{l}\text { importante na escolha de uma } \\
\text { profissão. }\end{array}\end{array}$ & $1,3 \%$ & $13,2 \%$ & $13,2 \%$ & $39,5 \%$ & $32,9 \%$ & 4 \\
$\begin{array}{l}\text { Ter orientação detalhada é necessário } \\
\text { para a realização de uma tarefa. }\end{array}$ & $1,3 \%$ & $10,5 \%$ & $14,5 \%$ & $38,2 \%$ & $35,5 \%$ & 4 \\
$\begin{array}{l}\text { A melhor forma de se comunicar no } \\
\text { trabalho é por e-mail e mensagem de } \\
\text { texto. }\end{array}$ & $17,1 \%$ & $30,3 \%$ & $17,1 \%$ & $23,7 \%$ & $11,8 \%$ & 2 \\
\hline
\end{tabular}

Fonte: Autores (2017)

Quanto às características da geração no ambiente de trabalho, a partir da neutralidade das respostas para as afirmativas subsequentes na Tabela 8, observase que os participantes não necessariamente acreditam que o melhor meio de comunicação no trabalho seja por e-mails e mensagens. Pelo grande uso das redes sociais no seu cotidiano, as conversas "cara a cara" são mais atrativas para essa geração. Outro fator também relacionado à Geração Z no trabalho, apontado por Half (2015) e Addeco (2015), é que essa geração precisa de apoio e explicações detalhadas para execução de tarefas devido à grande rede de apoio que sempre esteve presente para essa geração. A moda de número 4 nas respostas da segunda afirmação da Tabela 8 corrobora com esse levantamento, alegando que os participantes deste estudo de fato acham necessárias explicações detalhadas de modo a completar tarefas com excelência, sem retrabalho.

As afirmações na Tabela 9 relatam a retenção e fidelidade da Geração $Z$ em relação às empresas em que trabalharão. Apresentando moda igual a 1, ambas as afirmações mostram que a maior parte dos participantes acredita que fazer carreira em apenas uma empresa ao longo de sua vida não é algo desejável para sua vida profissional. Os respondentes não pensam em passar mais de três anos em seus primeiros empregos, mostrando que a rotatividade tende a crescer com a entrada dessa geração no mercado. 
Tabela 9 - Resultados das Afirmações sobre Carreira Profissional

\begin{tabular}{lcccccc}
\hline & 1 & 2 & 3 & 4 & 5 & Moda \\
\hline $\begin{array}{l}\text { Três anos é o período mínimo para } \\
\text { ficar no primeiro emprego. }\end{array}$ & $44,7 \%$ & $21,1 \%$ & $22,4 \%$ & $6,6 \%$ & $5,3 \%$ & 1 \\
$\begin{array}{l}\text { É desejável fazer carreira em apenas } \\
\text { uma empresa. }\end{array}$ & $42,1 \%$ & $27,6 \%$ & $18,4 \%$ & $6,6 \%$ & $5,3 \%$ & 1 \\
\hline
\end{tabular}

Fonte: Autores (2017)

\section{CONSIDERAÇÕES FINAIS}

Por meio da pesquisa realizada, foi observado que, em grande parte, os fatores da literatura estudada de fato condiziam com os fatores dos discentes participantes, devido ao grau de concordância dos resultados com a base teórica. Esses fatores concordantes se devem ao modo como a geração foi criada, o mundo à sua volta que os molda de forma igual, e também a forma como foram ensinados a verem situações ao seu entorno. Assim, é possível afirmar que os discentes, de fato, pertencem à Geração Z.

Porém, como pôde ser visto, também houveram poucas afirmações cujas respostas estavam em discordância com a literatura. Essa discordância pode ser explicada pelo fato de que os autores da literatura descrevem a geração como um todo, sem levar em consideração os subgrupos que existem entre as mesmas, que podem obter certas características peculiares e distintas do restante da geração. Pelo fato do foco do presente estudo ser os discentes de um curso de Engenharia, os mesmos possuem certas facetas que são peculiares para a sua formação e que são destoantes dos demais integrantes da geração devido à necessidade dos mesmos desenvolverem habilidades específicas para o seu curso, conforme discutido durante a análise das respostas.

Com base nos resultados obtidos, é possível verificar que os discentes de Engenharia de Produção possuem as principais características necessárias para os líderes do futuro, como: Raciocínio Sistêmico, Competência Intercultural, Treinamento Intensivo e Contínuo, e Padrões Pessoais e de Comportamento. Desta forma a Geração Z, como futuros líderes, será responsável por fomentar e executar mudanças na cultura das empresas para garantir a sobrevivência das mesmas no ambiente dinâmico que estão inseridas. 
Este trabalho não teve como objetivo determinar quais mudanças ocorrerão nas empresas do futuro, mas possibilitar, por meio da análise das características dos discentes, a criação de cenários das possíveis mudanças que a liderança da Geração Z poderá promover na cultura das empresas. Como uma hipótese de cenário é possível afirmar que as empresas continuarão a valorizar os profissionais multitarefas e exigirão de todos os colaboradores o conhecimento social, incluindo aqueles com cargos técnicos. A busca pela excelência, em conjunto com o aperfeiçoamento contínuo e o caráter imediatista desta geração, poderá criar um mercado de trabalho ainda mais competitivo, onde a capacidade do funcionário será medida através da entrega de resultados de curto e médio prazo, e a liderança cobrará resultados sempre acima do esperado. A rotatividade nas empresas poderá aumentar, principalmente em cargos de confiança, e as empresas precisarão focar em estratégias de retenção de talentos, criando programas de responsabilidade social. Graças à visão de igualdade desta geração, é possível que no futuro as diferenças salariais entre pessoas que exercem o mesmo cargo sejam menores.

Portanto, este trabalho possibilita a visibilidade do cenário atual da Geração Z, com base nos futuros Engenheiros de Produção, oferecendo aos interessados um conhecimento sobre suas características. A percepção dessa população pode ser utilizada pelas empresas como fonte de vantagem competitiva no mercado, verificando se suas características condizem com as estratégias e necessidades atuais das empresas e desenvolvendo mudanças internas para reter estes talentos.

\section{REFERÊNCIAS}

ABEPRO - ASSOCIAÇÃO BRASILEIRA DE ENGENHARIA DE PRODUÇÃO. Engenharia de Produção: Grande Área e Diretrizes Curriculares. Disponível em:

http://www.abepro.org.br/arquivos/websites/1/DiretrCurr19981.pdf. Acesso em: 12 set. 2017.

ADDOR, M.L. Generation Z: What is the Future of Stakeholder Engagement?. Institute for EMERGING ISSUES - NC State University. Disponível em: https://iei.ncsu.edu/wpcontent/uploads/2013/01/GenZStakeholders2.pdf. Acesso em: 29 mar. 2017.

ADECCO. Generation Z vs. Millennials. Disponível em: http://pages.adeccousa.com/rs/107IXF-539/images/generation-Z-vs-millennials.pdf. 2015. Acesso em: 07 abr. 2017.

ANDRADE, Maria M de. Introdução à metodologia do trabalho científico. 10. ed. São Paulo: Atlas, 2010. 
BARTLETT, C. A.; GHOSHAL, S. The myth of the generic manager: new personal competencies for new management roles. Califórnia Management Review, v. 40, n. 1, p. 93-116, 1987. https://doi.org/10.2307/41165924

BILHIM, João. Mudança Organizacional. In: COSTA, Silvia Generali da; VIEIRA, Leandro; RODRIGUES, Jorge Nascimento (Orgs.). Gestão da mudança: explorando o comportamento organizacional. São Paulo: Atlas, 2010.

CARR, Nicholas. A geração superficial: o que a internet está fazendo com os nossos cérebros. Tradução de Mônica Gagliotti Fortunato Friaça. Rio de Janeiro: Agir, 2011.

CAZALEIRO, Luiz Eduardo Fernandes. Práticas da liderança: um contraste entre geração $X$ e geração Y. 2011. 70f. Monografia (Bacharelado) - Universidade de Brasília, Departamento de Administração, Brasília, 2011.

CHIAVENATO, Idalberto. Gestão de pessoas: o novo papel dos recursos humanos nas organizações, 19º Triagem. Rio de Janeiro: Elsevier, 1999.

COLBERT, Amy; YEE, Nick; GEORGE, Gerard. The digital workforce and the workplace of the future. Academy of Management Journal, v. 59, n. 3, p. 731-739, 2016.

https://doi.org/10.5465/amj.2016.4003

DIAS, R. Cultura organizacional. Campinas: Alínea, 2003.

DIAS, Reinaldo. Cultura organizacional: construção, consolidação e mudanças. São Paulo: Atlas, 2013.

DRUCKER, Peter Ferdinand. Administrando em tempos de grandes mudanças. São Paulo: Pioneira, 2003.

FLEURY, M. T.; FISCHER, R. M. Cultura e poder nas organizações. São Paulo: Atlas, 1989.

FLEURY, A. \& FLEURY, M.T.L. Aprendizagem e inovação organizacional: as experiências de Japão, Coréia e Brasil. 2. ed. São Paulo: Atlas, 2011.

FONSECA, J. J. S. Metodologia da pesquisa científica. Fortaleza: UEC, 2002. Apostila.

FORQUIN, Jean-Claude. Relações entre gerações e processos educativos: transmissões e transformações. In: CONGRESSO INTERNACIONAL CO-EDUCAÇÃO DE GERAÇÕES. Anais [...]. São Paulo: SESC, outubro 2003.

GIL, Antonio C. Métodos e técnicas da pesquisa Social. 3. ed. São Paulo: Atlas, 2008.

GOLDENBERG, Mirian. A arte de pesquisar: como fazer uma pesquisa qualitativa em ciências sociais. 8. ed. Rio de Janeiro: Record, 2004.

HALF, Robert. Get ready for generation Z. Disponível em: https://www.roberthalf.com/workplace-research/get-ready-for-generation-z. Acesso em: 30 mar. 2017. 
HAMEL, Gary; PRAHALAD, C. K. Competindo pelo futuro: estratégia inovadoras para obter o controle do seu setor e criar os mercados de amanhã. 8. ed. Rio de Janeiro: Campus, 1999.

KOTTER, John P.; HESKETT, James L. A cultura corporativa e o desempenho empresarial. São Paulo: Makron Books, 1994.

LAKATOS, E. M.; MARCONI, M. de A. Fundamentos de metodologia científica. 7. ed. rev. e ampl. São Paulo: Atlas, 2010.

MENETTI, Sandra Aparecida Pagliaci Pulino. O comprometimento organizacional da Geração Y no setor de conhecimento intensivo. Dissertação (Mestrado) - USCS, Universidade Municipal de São Caetano do Sul, Programa de Mestrado em Administração, 2013. Disponível em:

http://www.uscs.edu.br/posstricto/administracao/dissertacoes/2013/pdf/DissertacaoSANDRA FINALABRIL2013.pdf. Acesso em: 05 abr. 2017.

NGUYEN, D. Q.; PUDLOWSKI, Z. J. The perspective of African Students on Environmental Education in Engineering Courses in the Republic of South Africa. Global Journal of Engineering Education, Melbourne, v.2, n.2, p. 169-176, 1998. Disponível em: www.eng.monash.edu.au/uicee/gjee. Acesso em: 25 ago. 2017

PACKARD, D. The HP way. New York: HarperCollins, 1995.

SCHEIN, Edgar H. Cultura Organizacional e liderança. São Paulo, Atlas, 2009.

SCHEIN, Edgar H. Guia de sobrevivência da cultura corporativa. Rio de Janeiro: José Olympio, 2001.

SERRANO, Daniel Portillo. Geração X, geração Y, geração Z. 2010. Disponível em: http://www.portaldomarketing.com.br. Acesso em: 24 mar. 2017.

SIMON, Fernanda Oliveira. Habilidades e competências em engenharia: criação e validação de um instrumento. Campinas, São Paulo, 2004.

WILLIAMS, Alex. Move Over, Millennials, Here Comes Generation Z. Disponível em: https://www.nytimes.com/2015/09/20/fashion/move-over-millennials-here-comes-generationz.html? r=0. 2012. Acesso em: 12 abr. 2017.

WOOD JR, T. Mudança organizacional: uma abordagem preliminar. Revista de Administração de Empresas, São Paulo, v.32, n.3, p. 74-87, 1992. https://doi.org/10.1590/S0034-75901992000300009

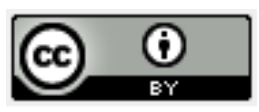

Artigo recebido em:31/03/2019 e aceito para publicação em: 16/08/2019 DOI: http://dx.doi.org/10.14488/1676-1901.v19i3.3600 